\title{
Recent Update on Microbiological Monitoring of Gastrointestinal Endoscopes after High-Level Disinfection
}

\author{
Suk Pyo Shin and Won Hee Kim \\ Digestive Disease Center, CHA Bundang Medical Center, CHA University, Seongnam, Korea
}

Endoscopy-related infections are important contributors to nosocomial infections. Endoscope reprocessing according to standard guidelines ensures high-level disinfection and prevents endoscopy-related infections. Microbiological surveillance may help in monitoring the effectiveness of gastrointestinal endoscope disinfection. The process involves microbial cultures and non-culture methods such as bioburden assays, adenosine triphosphate (ATP) bioluminescence, and quantitative polymerase chain reactions (PCRs). Surveillance culturing to monitor endoscopes after reprocessing has been recommended by a majority of organizations. Bioburden assays, ATP bioluminescence, and quantitative PCRs provide rapid and reliable measures. Each institution will have to try to establish its own surveillance guidelines. Clin Endosc 2015;48:369-373

Key Words: Endoscopes, gastrointestinal; Reprocessing; Monitoring

\section{INTRODUCTION}

Flexible endoscopes are essential instruments for the diagnosis and treatment of many digestive disorders. They have very complex structures made up of fibrotic bundles and multiple long narrow tubular channels. Endoscopes are connected to an air and water system and a suction system. Furthermore, because endoscopes are reusable, there have been many concerns about their transmission of pathogens. ${ }^{1}$

In a comprehensive review article, 281 cases of pathogen transmission via gastrointestinal (GI) endoscopes were recorded to have occurred from 1966 to 1992. Of these, 253 cases predated the adoption of endoscopic society guidelines established in 1988, ${ }^{2}$ and only 35 cases of infection transmission have been reported over the 10 years following $1993 .{ }^{3} \mathrm{Im}$ proper cleaning and disinfection procedures were responsible

Received: August 10, 2015 Revised: August 31, 2015

Accepted: September 9, 2015

Correspondence: Won Hee Kim

Digestive Disease Center, CHA Bundang Medical Center, CHA University, 59 Yatap-ro, Bundang-gu, Seongnam 13496, Korea

Tel: +82-31-780-5641, Fax: +82-31-780-5219, E-mail: arimd@naver.com

(c) This is an Open Access article distributed under the terms of the Creative Commons Attribution Non-Commercial License (http://creativecommons.org/ licenses/by-nc/3.0) which permits unrestricted non-commercial use, distribution, and reproduction in any medium, provided the original work is properly cited. for the majority of infection transmissions. ${ }^{2,3}$

Improper endoscope reprocessing, damaged endoscopes, contaminated automated endoscope reprocessors (AERs), and the complex structure of endoscopes can all threaten the safety of patients undergoing endoscopy. Therefore, endoscopic societies have established guidelines for the proper reprocessing of endoscopes. Most guidelines recommend multiple steps consisting of precleaning, cleaning, disinfection, rinsing, drying, and storage. ${ }^{4,5}$ Because endoscopes are categorized as semi-critical devices according to the Spaulding classification system, high-level disinfection (HLD) for reprocessing is needed. ${ }^{6,7}$ Because of the enforcement of proper endoscope reprocessing, the risk of microbial transmission has been greatly reduced.

In 2013, New Delhi metallo- $\beta$-lactamase-producing Escherichia coli and Klebsiella pneumoniae carbapenemase-producing K. pneumoniae were obtained by culture from the elevator channel of the endoscopic retrograde cholangiopancreatography (ERCP) endoscope. Although manual cleaning and HLD had been performed in accordance with the guidelines, these infections nevertheless occured. ${ }^{8}$ Lapses in proper endoscope reprocessing therefore still threaten the safety of patients.

In this respect, improved quality control systems would reduce patient safety concerns and substantially prevent 
infections from endoscopy. As part of the quality control of endoscope reprocessing, microbiological monitoring of endoscopes and their related facilities after HLD is being recommended by many organizations, such as the American Society for Gastrointestinal Endoscopy, the European Society of Gastrointestinal Endoscopy (ESGE), the European Society of Gastroenterology and Endoscopy Nurses and Associates (ESGENA) committee, and the Gastroenterological Society of Australia (GESA). ${ }^{4,9,10}$

\section{MICROBIOLOGICAL SURVEILLANCE: CULTURE AND NON-CULTURE METHODS}

Microbiological surveillance methods can be classified into two kinds: microbial culture and non-culture methods. Non-culture methods consist of bioburden assays, adenosine triphosphate (ATP) bioluminescence, and quantitative polymerase chain reactions (PCRs).

\section{Microbial culture}

The majority of organizations recommend microbial cultures for monitoring. The ESGE recommends that surveillance cultures be assessed at intervals of not more than 3 months. Moreover, the maximal total microbiological count should be $<20$ colony-forming units (cfu) for fluid collected after flushing the endoscope channels with $20 \mathrm{~mL}$ of sterile saline solution, with placement of $1 \mathrm{~mL}$ of the fluid on each agar plate. ${ }^{9}$ However, the accessibility to microbiology laboratories and the relative slow turnaround time make this method impractical, ${ }^{11}$ and standard culture methods cannot isolate viruses. ${ }^{4}$ Nevertheless, surveillance culturing to monitor endoscopes after reprocessing has been widely accepted because of its simple methodology and cost effectiveness, as well as the large number of accumulated studies supporting its use. .2-14 $^{-14}$

\section{Bioburden assays}

Bioburden assays detect proteins on the surface of endoscopes; protein and blood materials within the biopsy channel of endoscopes; and proteins, blood, and carbohydrates residing within the channel of endoscopes. ${ }^{9}, 11$ These assays are easy to use and can produce rapid results. Furthermore, several commercial test kits are available, such as Scope-Check (Valisafe America, Tampa, FL, USA) and EndoCheck and ChannelCheck (Health Mark Industries, Fraser, MI, USA). Surface sampling with swabs, channel sampling with swabs, and sterile water flushing are conducted, and the swab or water sample is then mixed with the test reagent. It takes 10 to 90 seconds for results to be obtained. The proposed criteria for organic and bioburden residues remaining after proper manual cleaning and before HLD include $<6.4 \mathrm{mg} / \mathrm{cm}^{2}$ of protein, $<1.2 \mathrm{mg} / \mathrm{cm}^{2}$ of carbohydrate, and $<2.2 \mathrm{mg} / \mathrm{cm}^{2}$ of hemoglobin. ${ }^{15}$

\section{Adenosine triphosphate bioluminescence}

Because ATP is present in microorganisms and cells, this test enables estimation of the contamination condition after reprocessing. The technique uses the light-producing reaction between ATP, luciferin, and luciferase to estimate the levels of ATP in a sample. The results can be obtained within a few minutes. Luminometers convert the number of photons released in the reaction into relative light units (RLUs). The proposed criterion is achieved when the bioluminescence reading is $<200$ RLUs. ${ }^{16}$ The sensitivity is 0.46 to 0.75 and the specificity is 0.43 to 0.81 , compared with routine microbiological culturing. Although it does not seem appropriate to replace routine microbiological culturing with the ATP bioluminescence assay, ${ }^{17}$ ATP bioluminescence can provide a rapid and reliable measure of the effectiveness of the cleaning step prior to terminal disinfection. ${ }^{18,19}$ The Centers for Disease Control and Prevention (CDC) protocol comments that non-culture methods such as ATP bioluminescence need systemic validation owing to a lack of consistent correlation to bacterial concentrations. $^{20}$

\section{Polymerase chain reaction}

PCRs have been used for detecting the human immunodeficiency virus, hepatitis B virus, hepatitis C virus, and Helicobacter pylori. Even if the test result is positive; however, it does not necessarily mean a presence of infectivity. ${ }^{21-23}$ As part of the new non-culture-based methods, measurement or quantitative PCR for monitoring needs to be further optimized because of its low specificity. ${ }^{24}$

\section{MICROBIOLOGICAL MONITORING BY MULTIPLE ORGANIZATIONS/ INVESTIGATORS}

Many organizations and investigators recommend microbiological surveillance of endoscopes, but some do not. The French Gastroenterology Society, ${ }^{25}$ ESGE-ESGENA, the GESA and the Gastroenterological Nurses College of Australia (GESA-GENCA), and the New Zealand Standards Expert Committee (SNZ HB) recommend microbiological surveillance testing of endoscopes after reprocessing in their guidelines. Although guidelines in the USA do not recommend routine culturing, the $\mathrm{CDC}$ has introduced the surveillance culture methods of other international guidelines. ${ }^{20}$ Moreover, there are some disparities among the guidelines for microbiological monitoring, in that the surveillance frequency, sampling methods, and sampling sites are different. 
Table 1. Sampling Methods and Sites and Frequency of Microbiological Surveillance Culturing Set by Different Guidelines

\begin{tabular}{|c|c|c|c|}
\hline Guidelines (year) & Sampling method & Sampling site & Surveillance frequency \\
\hline APIC (2000) & Flushing, brushing & $\begin{array}{l}\text { Suction/biopsy, air/water, eleva- } \\
\text { tor, and carbon dioxide channel }\end{array}$ & Routine test not recommended \\
\hline ESGE-ESGENA (2008) & $\begin{array}{l}\text { Anterograde flush: channels } \\
\text { Swabs: outer surfaces } \\
\text { Liquid samples: water bottles }\end{array}$ & $\begin{array}{l}\text { All channels } \\
\text { Outer surfaces } \\
\text { Connected water bottle }\end{array}$ & No longer than 3 months \\
\hline BSG (2008) & $\begin{array}{l}\text { For atypical mycobacteria } \\
\text { Rinse water: AER }\end{array}$ & AER & Annual \\
\hline Canada (2010) & Anterograde flush & $\begin{array}{l}\text { Suction/biopsy and air/water } \\
\text { channels }\end{array}$ & Routine test not recommended \\
\hline GESA-GENCA (2010) & $\begin{array}{l}\text { Flush-brush-flush: channels } \\
\text { Anterograde sampling supported by } \\
\text { retrograde sampling } \\
\text { Flushing with filter: AER } \\
\text { Liquid samples: water bottles }\end{array}$ & $\begin{array}{l}\text { All channels } \\
\text { AER } \\
\text { Water for manual rinsing or water } \\
\quad \text { supply to AER }\end{array}$ & $\begin{array}{l}\text { AER, duodenoscopes: every } 4 \\
\text { weeks } \\
\text { Other GI endoscopes: every } 3 \\
\text { months }\end{array}$ \\
\hline ASGE (2011) & & & Routine test not recommended \\
\hline UMCG (2011) & Retrograde flushing & $\begin{array}{l}\text { Suction/biopsy and air/water } \\
\text { channels }\end{array}$ & $\begin{array}{l}\text { Therapeutic gastro/ } \\
\text { duodenoscopes: monthly } \\
\text { Diagnostic endoscopes: every } 3 \\
\text { months }\end{array}$ \\
\hline CDC (2015) & $\begin{array}{l}\text { Brush: distal end of the duodenos- } \\
\text { cope } \\
\text { Anterograde flush: channels }\end{array}$ & $\begin{array}{l}\text { Instrument channels and distal } \\
\text { end of the duodenoscope }\end{array}$ & Routine test not recommended \\
\hline
\end{tabular}

APIC, Association for Professionals in Infection Control and Epidemiology; ESGE-ESGENA, European Society of Gastrointestinal Endoscopy and European Society of Gastroenterology and Endoscopy Nurses and Associates; BSG, British Society of Gastroenterology; AER, automated endoscope reprocessor; GESA-GENCA, Gastroenterological Society of Australia and Gastroenterological Nurses College of Australia; GI, gastrointestinal; ASGE, American Society for Gastrointestinal Endoscopy; UMCG, University Medical Center Groningen; CDC, Centers for Disease Control and Prevention.

\section{Surveillance frequency}

The GESA recommends microbiological surveillance every 4 weeks on AERs and duodenoscopes and every 3 months on other GI endoscopes. The ESGE-ESGENA guideline committee recommends the intervals to be no longer than 3 months. The British Society of Gastroenterology (BSG) guidelines recommend annual surveillance testing.

\section{Sampling methods and sites}

Sampling from the channel of the endoscope can be performed in an anterograde or retrograde manner. Anterograde sampling refers to collection of the last-rinse water at the distal end of the endoscope. Retrograde sampling refers to collection of the water that is flushed from the distal end to the proximal end. Because retrograde sampling is considered more sensitive than anterograde sampling, the former is recommended for monitoring endoscopes after reprocessing. ${ }^{24,26}$ Flushing or flush-brush-flush methods for sampling of the internal channel are introduced in some studies and guidelines.

Table 1 shows the sampling methods and sites and frequency of microbiological surveillance culturing set by different guidelines.

\section{Surveillance culture target}

It is hard to test routinely for all species of bacteria, fungi, and viruses, so a culture target has to take into account the objective and cost. The BSG guidelines recommend annual testing for atypical mycobacteria in AERs. In the ESGE-ESGENA guidelines, Enterobacteriaceae, Pseudomonas aerugino$s a$, and staphylococci should be tested as indicator organisms, and atypical mycobacteria culture is recommended. The GESA-GENCA guidelines do not recommend routine testing for Legionella spp., anaerobes, $H$. pylori, and viruses. They recommend that bacterial cultures be directed to the detection of oral and enteric microorganisms such as coliforms (including Salmonella), enterococci, and viridans streptococci (but not anaerobes), as well as non-fermentative gram-negative bacilli (including Pseudomonas spp.). In samples from automated processors, non-fermentative gram-negative bacilli (including Pseudomonas spp.) and rapid-growing mycobacteria are the targets.

In the University Medical Center Groningen guidelines, 
bacterial isolates and yeasts are identified according to standard determination schemes. ${ }^{27}$

\section{Culture results and interpretation}

It is important to know how to interpret the culture results and what to do with the results. In the BSG guidelines, the presence of skin and environmental contaminants is not interpreted as a failure of disinfection. It simply means that endoscopes are not handled in a sterile fashion after decontamination. In the ESGE-ESGENA guidelines, growth of Enterobacteriaceae means insufficient cleaning and/or disinfection procedures, whereas growth of $P$. aeruginosa implies insufficient final rinsing and/or insufficient drying of endoscopes before storage. Growth of staphylococci results from endoscope recontamination. In the case of atypical mycobacteria (Legionella organisms) growth, contamination of the washer-disinfector and water system is suspected. For channels, the total microbiological count should be $<20 \mathrm{cfu} /$ channel; for water samples, it should be $<10 \mathrm{cfu} / 100 \mathrm{~mL}$. According to GESA-GENCA indications, growth of low numbers of skin microorganisms means contamination during the collection process rather than a significant problem with the disinfection or cleaning process, whereas growth of Pseudomonas spp. or other non-fermentative gram-negative bacilli is cause for serious and immediate concern and response. The repeated growth of significant numbers of enteric microorganisms from one instrument implies a mechanical defect in that instrument. Significant numbers of enteric microorganisms from a variety of instruments are most likely a result of inadequate reprocessing. The isolation of any Salmonella or Shigella species is a cause for concern.

\section{CONCLUSIONS}

Endoscopy-related infections can cause serious morbidity and therefore require attention from both patients and physicians. The need to obey every step of endoscope reprocessing meticulously cannot be over-emphasized. The majority of endoscopy-related infections are preventable with precise and careful endoscope reprocessing. However, factors such as endoscope damage, faulty AERs, and biofilms inside the endoscopic channels are attributable to endoscopy-related infections despite of meticulous reprocessing. Therefore, microbial monitoring is important. Unfortunately, all guidelines are inconsistent concerning the frequency and method of the microbiological monitoring. Although daily or per procedure real-time monitoring is ideal, this is currently not possible. Individual institutions should establish their own guidelines for microbiological monitoring, taking into consideration institutional cost and environmental factors.
Conflicts of Interest

The authors have no financial conflicts of interest.

\section{REFERENCES}

1. Nelson DB, Barkun AN, Block KP, et al. Technology status evaluation report. Transmission of infection by gastrointestinal endoscopy. May 2001. Gastrointest Endosc 2001;54:824-828.

2. Nelson DB, Muscarella LF. Current issues in endoscope reprocessing and infection control during gastrointestinal endoscopy. World J Gastroenterol 2006;12:3953-3964.

3. Spach DH, Silverstein FE, Stamm WE. Transmission of infection by gastrointestinal endoscopy and bronchoscopy. Ann Intern Med 1993;118:117-128.

4. ASGE Quality Assurance In Endoscopy Committee, Petersen BT, Chennat J, et al. Multisociety guideline on reprocessing flexible gastrointestinal endoscopes: 2011. Gastrointest Endosc 2011;73:1075-1084.

5. Lee YK, Park JB. Steps of reprocessing and equipments. Clin Endosc 2013;46:274-279.

6. Spaulding EH. Chemical disinfection and antisepsis in the hospital. J Hosp Res 1972;9:5-31.

7. Chiu KW, Lu LS, Chiou SS. High-level disinfection of gastrointestinal endoscope reprocessing. World J Exp Med 2015;5:33-39.

8. Centers for Disease Control and Prevention (CDC). Notes from the Field: New Delhi metallo-beta-lactamase-producing Escherichia coli associated with endoscopic retrograde cholangiopancreatography - Illinois, 2013. MMWR Morb Mortal Wkly Rep 2014;62:1051.

9. Beilenhoff U, Neumann CS, Rey JF, et al. ESGE-ESGENA guideline for quality assurance in reprocessing: microbiological surveillance testing in endoscopy. Endoscopy 2007;39:175-181.

10. Saviuc P, Picot-Guéraud R, Shum Cheong Sing J, et al. Evaluation of the quality of reprocessing of gastrointestinal endoscopes. Infect Control Hosp Epidemiol 2015;36:1017-1023.

11. ASGE Technology Committee, Komanduri S, Abu Dayyeh BK, et al. Technologies for monitoring the quality of endoscope reprocessing. Gastrointest Endosc 2014;80:369-373.

12. Moses FM, Lee J. Surveillance cultures to monitor quality of gastrointestinal endoscope reprocessing. Am J Gastroenterol 2003;98:77-81.

13. Chiu KW, Fong TV, Wu KL, et al. Surveillance culture of endoscope to monitor the quality of high-level disinfection of gastrointestinal reprocessing. Hepatogastroenterology 2010;57:531-534.

14. Chiu KW, Tsai MC, Wu KL, Chiu YC, Lin MT, Hu TH. Surveillance cultures of samples obtained from biopsy channels and automated endoscope reprocessors after high-level disinfection of gastrointestinal endoscopes. BMC Gastroenterol 2012;12:120.

15. Alfa MJ, Olson N, Degagné P, Simner PJ. Development and validation of rapid use scope test strips to determine the efficacy of manual cleaning for flexible endoscope channels. Am J Infect Control 2012;40:860865.

16. Alfa MJ, Fatima I, Olson N. Validation of adenosine triphosphate to audit manual cleaning of flexible endoscope channels. Am J Infect Control 2013;41:245-248

17. Hansen D, Benner D, Hilgenhöner M, Leisebein T, Brauksiepe A, Popp W. ATP measurement as method to monitor the quality of reprocessing flexible endoscopes. Ger Med Sci 2004;2:Doc04.

18. Obee PC, Griffith CJ, Cooper RA, Cooke RP, Bennion NE, Lewis M. Real-time monitoring in managing the decontamination of flexible gastrointestinal endoscopes. Am J Infect Control 2005;33:202-206.

19. Fushimi R, Takashina M, Yoshikawa H, et al. Comparison of adenosine triphosphate, microbiological load, and residual protein as indicators for assessing the cleanliness of flexible gastrointestinal endoscopes. Am J Infect Control 2013;41:161-164.

20. Centers for Disease Control and Prevention. Interim protocol for 
healthcare facilities regarding surveillance for bacterial contamination of duodenoscopes after reprocessing [Internet]. Atlanta: CDC; 2015 [updated 2015 Apr 3; cited 2015 Sep 14]. Available from: http://www.cdc. gov/hai/organisms/cre/cre-duodenoscope-surveillance-protocol.html.

21. Deva AK, Vickery K, Zou J, et al. Detection of persistent vegetative bacteria and amplified viral nucleic acid from in-use testing of gastrointestinal endoscopes. J Hosp Infect 1998;39:149-157.

22. Tsuji S, Kawano S, Oshita M, et al. Endoscope disinfection using acidic electrolytic water. Endoscopy 1999;31:528-535.

23. Roosendaal R, Kuipers EJ, van den Brule AJ, et al. Detection of Helicobacter pylori DNA by PCR in gastrointestinal equipment. Lancet 1993;341:900.

24. Kovaleva J, Peters FT, van der Mei HC, Degener JE. Transmission of infection by flexible gastrointestinal endoscopy and bronchoscopy. Clin Microbiol Rev 2013;26:231-254.

25. Systchenko R, Marchetti B, Canard JN, et al. Guidelines of the French Society of Digestive Endoscopy: recommendations for setting up cleaning and disinfection procedures in gastrointestinal endoscopy. Endoscopy 2000;32:807-818.

26. Buss AJ, Been MH, Borgers RP, et al. Endoscope disinfection and its pitfalls: requirement for retrograde surveillance cultures. Endoscopy 2008;40:327-332.

27. Kovalena J, Buss A. Usefulness of bacteriological monitoring of endoscope reprocessing. In: Pascu P, Tantau P, eds. Therapeutic Gastrointestinal Endoscopy. Rijeka: InTech; 2011. p. 141-162. 